\title{
Psychiatric symptoms, substance use, and other medical conditions in patients with obesity who seek treatment for weight loss
}

\author{
Rodrigo Marín-Navarrete, ${ }^{1}$ Javier Quintero, ${ }^{2}$ Javier Correas-Lauffer, ${ }^{3}$ Julio Cortés-Ramírez, ${ }^{4}$ Luis Villalobos-Gallegos ${ }^{1}$
}

\section{Original article}

\section{ABSTRACT}

Introduction

Scaling in obesity classes increases its effect on medical comorbidities and psychiatric symptoms. Anxiety and depression have a significant effect on treatment adherence and weight loss.

\section{Objective}

This study had three aims: a) to evaluate the prevalence of psychiatric symptoms; b) to evaluate the interactions between obesity classes and demographic variables in relation to psychiatric symptoms; and c) to analyze the interactions between obesity classes, demographic variables, and psychiatric symptoms in association with medical comorbidities in a sample of obese individuals seeking treatment for weight loss.

\section{Method}

Medical record review of 22 weight loss clinics during January-December 2014. Binomial logistic regression was carried to assess univariate associations, second- and third-order interactions.

\section{Results}

Total sample was composed of 13,305 patients, mostly women $(82.04 \%)$, married $(53.66 \%)$, with elementary education $(38.6 \%)$, mean body max index was 34.94 (SD = 4.39). The most prevalent psychiatric symptoms were anxiety $(45.21 \%)$ and depression $(16.36 \%)$. When analyzing interactions, it was found that men with class II obesity had higher odds for alcohol use (OR 1.56, IC 95\% 1.10-2.22), and participants with obesity class III and married had more probability of diabetes II (OR 1.53, IC 95\% 1.06-2.19).

\section{Discussion and conclusion}

Results show the complexity of the relation between demographic variables, psychiatric symptoms, medical comorbidities and obesity, underscoring the need to tailor treatments based in such variables, to promote adherence and weight loss.

Key words: Psychiatric symptoms, obesity, substance use, weight reduction programs.

\section{RESUMEN}

\section{Introducción}

El incremento en el grado de obesidad se asocia con comorbilidades médicas y los síntomas psiquiátricos. La ansiedad y la depresión afectan la adherencia al tratamiento de la obesidad y la reducción de peso corporal.

\section{Objetivo}

El estudio tuvo tres objetivos principales: a) Evaluar la prevalencia de síntomas psiquiátricos; b) evaluar las interacciones entre grados de obesidad, variables demográficas y síntomas psiquiátricos; c) analizar las interacciones entre grados de obesidad, síntomas psiquiátricos y comorbilidades médicas.

\section{Método}

A través de revisión de expedientes médicos de 22 clínicas de reducción de peso entre enero-diciembre de 2014 . Se analizó a través de regresión logística univariada y evaluando interacciones de segundo $y$ tercer orden.

\section{Resultados}

La muestra total fue de 13305 , mayormente mujeres (82.04\%) la mayoría son casados $(53.66 \%)$ con escolaridad de secundaria $(38.6 \%)$ y preparatoria (36.7\%), el IMC promedio fue de 34.94 (SD = 4.39). Las comorbilidades más prevalentes fueron síntomas de ansiedad $(45.21 \%)$ y depresión (16.36\%). Al analizar las interacciones los hombres con obesidad tipo II tuvieron mayor probabilidad de consumo de alcohol (OR 1.56 IC 95\% 1.10-2.22), y los participantes con obesidad tipo III y casados tuvieron mayor probabilidad de diabetes (OR 1.53 IC $95 \%$ 1.06-2.19).

\section{Discusión y conclusión}

Los resultados muestran la compleja relación entre variables demográficas, obesidad, síntomas psiquiátricos y comorbilidades, implicando la necesidad de desarrollar programas de tratamiento que tomen en cuenta dichas variables para promover la adherencia al tratamiento y la reducción de peso.

Palabras clave: Sintomatología psiquiátrica, obesidad, consumo de sustancias, programas de reducción de peso.

Unidad de Ensayos Clínicos en Adicciones y Salud Mental, Instituto Nacional de Psiquiatría Ramón de la Fuente Muñiz, México.

Servicio de Psiquiatría, Hospital Universitario Infanta Leonor, Universidad Complutense de Madrid, España.

Hospital Universitario del Henares, Servicio de Psiquiatría y Salud Mental, España.

4 Facultad de Psicología, Universidad Nacional Autónoma de México, México.

Correspondence: Rodrigo Marín-Navarrete. Instituto Nacional de Psiquiatría Ramón de la Fuente Muñiz (INPRFM), Clinical Trials Unit on Addiction and Mental Health. Calz. México-Xochimilco 101, San Lorenzo Huipulco, Tlalpan, Zip. 14370, Mexico City. Phone: +52 554160 - 5480 . E-mail address: rmarin@imp.edu.mx

Received first version: April 22, 2016. Second version: May 2, 2016. Accepted: May 6, 2016. 


\section{INTRODUCTION}

International studies show that overweight and obesity are two of the medical conditions with the highest burden of disease ${ }^{1}$ and their risk of mortality increases when comorbidity with diabetes and hypertension is met. ${ }^{2-6}$ Current evidence shows that overweight and obesity have significant effects on several areas, diminishing quality of life and overall health. ${ }^{7-9}$

Obesity has not only shown high comorbidity with general medical conditions, but also with specific psychiatric comorbidities, ${ }^{10-12}$ such as depressive and anxiety disorders, substance abuse, and suicidality. ${ }^{12-18}$ This results in 1.18 times more probability of showing depression when compared to non-obese individuals, regardless of cultural background. ${ }^{19}$ Regarding suicide, studies have found that women with obesity have greater frequency of suicidal ideation and suicide attempts, compared to men with obesity. ${ }^{20}$

Few studies have associated body mass index (BMI) with substance use. Evidence indicates that overweight and obesity are related with a higher risk of alcohol use disorder in men, but not in women ${ }^{21}$ and that obesity and tobacco use significantly increases the risk of mortality. ${ }^{22,23}$ Furthermore, substance use in obese individuals increases 34\%-89\% after bariatric surgery. ${ }^{24}$

The study of psychiatric disorders in individuals with obesity is particularly relevant because these conditions are associated with low adherence to treatment, higher utilization of health services, and negative results in health examinations. ${ }^{25,26}$ Gender, age, socioeconomic status, and obesity class act as potential moderators in the relation between obesity and depression ${ }^{16,27,28}$ whereas gender differences are consistent with substance use and suicide. ${ }^{20,21}$ However, evidence is still controversial because of the possibility of interactions between sociodemographic variables and obesity.

It is relevant to state that Mexico is one of the countries with the highest rates of overweight and obesity. ${ }^{1}$ According to the Mexican Health and Nutrition Survey (ENSANUT, 2012), the prevalence of obesity (BMI $\geq 30$ ) and overweight (BMI between 25 and 29.9) in the Mexican population between the ages of $20-69$ is $32.4 \%$ and $38.8 \%$ respectively, with $73 \%$ of women and $69.4 \%$ of men showing either of these conditions..$^{29}$ Notwithstanding the impact of obesity in Mexico, few studies have evaluated the relation between mental disorders and substance use, and those that are available are derived from small samples ${ }^{30}$ and with specific populations, e.g. students. ${ }^{31}$

Considering that in Mexico the relation between obesity and mental disorders has not been sufficiently studied, the present work has the following objectives: a) to evaluate the prevalence of psychiatric symptoms; b) to evaluate the interactions between obesity classes and demographic variables in relation to psychiatric symptoms; and c) to an- alyze the interactions between obesity class, demographic variables, and psychiatric symptoms in association with medical comorbidities in a sample of individuals that seek treatment for obesity.

\section{METHOD}

\section{Design}

This analysis was developed following the methodology of Medical Record Review (MRR), ${ }^{32}$ which refers to any study that uses pre-recorded patient-focused data as the primary source of information to answer a research question.

The medical records were registered in the first contact with physicians at 22 outpatient community centers specialized in obesity and weight loss treatment in four states of Mexico (18 in Mexico City, one in Puebla, one in Morelos, and two in the State of Mexico). The centers comply with current Mexican regulations for outpatient primary care (NOM-178-SSA1-1998). Data was collected between January 2014 and December 2014.

\section{Study sample}

The medical records included in this analysis belong to patients who seek weight reduction treatment at outpatient community centers and endorsed obesity criteria established by the international standards from the World Health Organization (Class I: BMI of 30 to $34.9 \mathrm{~kg} / \mathrm{m}^{2}$, Class II: BMI of 35 to $39.9 \mathrm{~kg} / \mathrm{m}^{2}$; Class III or severe obesity: BMI greater than $\left.40 \mathrm{~kg} / \mathrm{m}^{2}\right) .{ }^{33}$ Records from patients younger than 18 years old were excluded from the analysis (figure 1).

\section{Measurements}

The medical assessment was integrated by: a) standardised clinical interview, b) point of care glucose testing, c) blood pressure (diastolic and systolic in $\mathrm{mm} / \mathrm{Hg}$ ), and $\mathrm{d}$ ) anthropometric measurements including: waist circumference (in

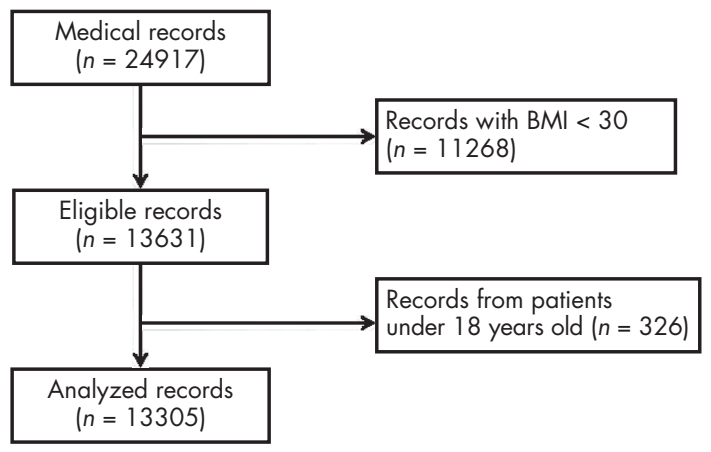

Figure 1. Medical records flowchart. 
Weight loss treatment and mental health

Table 1. Patients characteristics $(n=13305)$

\begin{tabular}{|c|c|c|c|c|c|}
\hline & \multicolumn{3}{|c|}{ Obesity classes } & \multirow[b]{2}{*}{ Total } & \multirow[b]{3}{*}{ Statistical differences } \\
\hline & I & $\|$ & III & & \\
\hline & $\begin{array}{l}\text { Mean (SD) } \\
\text { or Freq. }(\%)\end{array}$ & $\begin{array}{l}\text { Mean (SD) } \\
\text { or Freq. }(\%)\end{array}$ & $\begin{array}{l}\text { Mean }(\mathrm{SD}) \\
\text { or Freq. }(\%)\end{array}$ & $\begin{array}{l}\text { Mean }(S D) \\
\text { or Freq. }(\%)\end{array}$ & \\
\hline Age & $41.80(12.23)$ & $42.32(11.72)$ & $42.54(11.51)$ & 42.05 (12.01) & $F(2,13302)=3.49$ * \\
\hline Gender & & & & & $\chi^{2}(2)=2.24$ \\
\hline Women & 6605 (81.69) & 2973 (83.02) & 1337 (81.57) & 10915 (82.04) & \\
\hline Men & $1480(18.31)$ & 608 (16.98) & 302 (18.43) & $2390(17.96)$ & \\
\hline Marital status & & & & & $\chi^{2}(8)=25.80^{*}$ \\
\hline Married & 4457 (55.13) & 1876 (52.39) & 806 (49.18) & 7139 (53.66) & \\
\hline Divorced & $222(2.75)$ & $115(3.21)$ & $50(3.05)$ & $387(2.91)$ & \\
\hline Single & $2450(30.30)$ & 1172 (32.73) & 567 (34.59) & 4189 (31.48) & \\
\hline Cohabiting & $739(9.14)$ & $328(9.16)$ & $164(10.01)$ & $1231(9.25)$ & \\
\hline Widowed & $217(2.68)$ & $90(2.51)$ & $52(3.17)$ & 359 (2.70) & \\
\hline Education & & & & & $\chi^{2}(4)=28.78 *$ \\
\hline Elementary & 3034 (37.53) & 1391 (38.84) & 719 (43.87) & $5144(38.66)$ & \\
\hline High school & $2972(36.76)$ & 1331 (37.17) & $576(35.14)$ & 4879 (36.67) & \\
\hline College or more & 2079 (25.71) & 859 (23.99) & 344 (20.99) & 3282 (24.67) & \\
\hline Waist circumference & 101.71 (7.61) & $111.19(8.41)$ & 124.47 (11.79) & $107.06(11.43)$ & $F(2,13302)=5526.34^{*}$ \\
\hline Systolic pressure & 119.16 (14.62) & $122.56(15.00)$ & 127.37 (19.11) & 121.09 (15.59) & $F(2,13302)=217.67^{*}$ \\
\hline Diastolic pressure & 74.37 (14.51) & 77.07 (18.15) & 79.20 (11.59) & 75.69 (15.37) & $F(2,13302)=88.02^{*}$ \\
\hline Glucose level & 109.40 (43.09) & $111.36(40.88)$ & $118.45(48.85)$ & $111.04(43.36)$ & $F(2,13302)=29.96$ * \\
\hline
\end{tabular}

${ }^{*} p<.05$.

centimeters), height (in centimeters), weight (in kilograms) and BMI (in $\mathrm{kg} / \mathrm{cm}^{2}$ ). Diabetes II, hypertension and dyslipidemia cases were taken as stated in the patient's medical record.

To assess psychiatric symptoms and substance use, the standardised clinical interview used the following questions: depression symptoms "In the past 30 days have you felt significantly sad or depressed?"; anxiety symptoms "In the past 30 days have you felt significantly anxious or nervous?"; suicide attempt "In the past year have you made any suicide attempts?"; daily smoking "In the past year have you been smoking at least one cigarette per day?"; alcohol use "In the past year have you been drinking at least once per week?"; drug use "in the past year have you used any drug at least once?".

\section{Procedures}

The database was conformed from a community prevention and treatment program for obesity and weight loss sponsored by public institutions in 22 sites across Mexico City, the State of Mexico, Morelos, and Puebla. This community treatment program aimed to provide free medical care to individuals seeking treatment for weight loss. As a part of the procedures the physicians performed medical assessments and requested consent to use the patients' data for research. All physicians who participated in the medical assessment were certified in obesity and weight loss treatment.

\section{Ethical considerations}

Patients signed a written informed consent approving the use of their data for research purposes. A technical and ethical academic committee approved all procedures for this data analysis and to preserve confidentiality, the identification and localisation data of the patients wee de-identified in compliance with Mexican research regulations (NOM012-SSA3-2012), and international standards of good clinical practices for human research.

\section{Statistical analysis}

Demographic, medical and psychiatric variables were summarised using mean and standard deviation for numeric, frequencies and percentages for categorical variables. Univariate differences between three obesity classes were tested using one way ANOVA for numerical and chi square $\left(\chi^{2}\right)$ for categorical variables. A second step to test associations between obesity, demographics, medical and psychiatric variables was to perform univariate binomial logistic, then twoway interactions between obesity classes and demographic variables were tested for psychiatric variables, and two-way interactions between obesity classes, psychiatric and demographic variables were tested for medical variables. When two or more two-way interactions were significant, threeway interactions between the variables were tested. Statistical analyses were performed using R software v 3.2.3. Significance was set to $p<.05$. 
Table 2. Psychiatric and other medical comorbidities $(n=13305)$

\begin{tabular}{|c|c|c|c|c|c|c|c|c|c|}
\hline \multirow[b]{4}{*}{ Depressive symptoms } & \multicolumn{6}{|c|}{ Obesity classes } & \multirow{2}{*}{\multicolumn{2}{|c|}{ Total }} & \multirow{4}{*}{$\begin{array}{c}\text { Statistical differences } \\
\chi^{2}(2)=42.30^{*}\end{array}$} \\
\hline & \multicolumn{2}{|r|}{ I } & \multicolumn{2}{|r|}{$\|$} & \multicolumn{2}{|c|}{ III } & & & \\
\hline & \multicolumn{2}{|c|}{ Freq. (\%) } & \multicolumn{2}{|c|}{ Freq. (\%) } & \multicolumn{2}{|c|}{ Freq. (\%) } & \multicolumn{2}{|c|}{ Freq. $(\%)$} & \\
\hline & 1195 & (14.78) & 647 & (18.07) & 335 & $(20.44)$ & 2177 & $(16.36)$ & \\
\hline Anxiety symptoms & 3533 & $(43.70)$ & 1691 & (47.22) & 791 & (48.26) & 6015 & (45.21) & $\chi^{2}(2)=19.46^{*}$ \\
\hline Suicide attempt & 39 & $(0.48)$ & 20 & $(0.56)$ & 9 & $(0.55)$ & 68 & $(0.51)$ & $\chi^{2}(2)=0.33$ \\
\hline Tobacco use & 1087 & (13.44) & 501 & (13.99) & 190 & (1 1.59) & 1778 & (13.36) & $\chi^{2}(2)=5.70$ \\
\hline Drug use & 62 & $(0.77)$ & 26 & $(0.73)$ & 16 & $(0.98)$ & 104 & $(0.78)$ & $\chi^{2}(2)=0.96$ \\
\hline Alcohol use & 529 & (6.54) & 198 & (5.53) & 89 & (5.43) & 816 & (6.13) & $\chi^{2}(2)=6.03^{*}$ \\
\hline Diabetes II & 574 & (7.10) & 294 & (8.21) & 191 & (11.65) & 1059 & $(7.96)$ & $\chi^{2}(2)=38.99 *$ \\
\hline Dyslipidemia & 1802 & (22.29) & 839 & $(23.43)$ & 384 & (23.43) & 3025 & $(22.74)$ & $\chi^{2}(2)=2.35$ \\
\hline Hypertension & 1012 & (12.52) & 653 & (18.24) & 419 & $(25.56)$ & 2084 & $(15.66)$ & $\chi^{2}(2)=200.14^{*}$ \\
\hline
\end{tabular}

\section{RESULTS}

A total sample of 13,305 patients (records) met eligibility criteria, with a mean age of $42(S D=12)$ years old, and most of them were women, married, and with elementary or high school education. Mean BMI (SD) for obesity classes I, II and III were: 32.19 (1.41), 37.00 (1.40), and 43.97 (3.83) respectively; while in the whole sample mean BMI was 34.94 $(\mathrm{SD}=4.39$ ). Between groups (obesity class) significant differences were found in age, marital status, education, waist circumference, diastolic and systolic blood pressure, and glucose level (table 1).
Regarding the prevalence of psychiatric and other medical conditions, the most prevalent were: anxiety and depressive symptoms, dyslipidemia, and hypertension. Significant differences were found between groups for anxiety and depressive symptoms, alcohol use, diabetes, and hypertension (table 2).

When univariate predictors were added, most of the demographic and obesity classes were significant, excluding the association between obesity class III and alcohol use. The only significant second order interactions for anxiety symptoms were obesity class III by gender and obesity class II by age, while for alcohol use obesity class II by gender interaction was significant (table 3).

Table 3. Regression models for psychiatric symptoms $(n=13305)$

\begin{tabular}{|c|c|c|c|c|c|c|}
\hline & \multicolumn{2}{|c|}{ Depressive symptoms } & \multicolumn{2}{|c|}{ Anxiety symptoms } & \multicolumn{2}{|c|}{ Alcohol use } \\
\hline & OR & $95 \% \mathrm{Cl}$ & OR & $95 \% \mathrm{Cl}$ & OR & $95 \% \mathrm{Cl}$ \\
\hline \multicolumn{7}{|l|}{ Univariate regressions } \\
\hline Obesity class IIa & $1.27^{*}$ & $1.14-1.41$ & $1.15^{\star}$ & $1.08-1.33$ & $0.83^{*}$ & $0.70-0.98$ \\
\hline Obesity class IIIa & $1.48 *$ & $1.29-1.69$ & $1.20 *$ & $1.08-1.33$ & 0.82 & $0.65-1.03$ \\
\hline Gender $^{b}$ & $0.38 *$ & $0.32-0.45$ & $0.55^{*}$ & $0.50-0.61$ & $5.91 *$ & $5.11-6.84$ \\
\hline Age & $1.01 *$ & $1.00-1.01$ & $0.98 *$ & $0.98-0.98$ & $0.96 *$ & $0.95-0.96$ \\
\hline Elementary education & $0.70 *$ & $0.64-0.77$ & $1.25 *$ & $1.17-1.34$ & $2.42 *$ & $2.03-2.87$ \\
\hline Married & $0.84 *$ & $0.76-0.92$ & 1.01 & $0.94-1.08$ & $0.71 *$ & $0.62-0.82$ \\
\hline \multicolumn{7}{|l|}{ Second order interactions } \\
\hline Obesity class II x gender & 0.77 & $0.53-1.12$ & 1.08 & $0.87-1.35$ & $1.56 *$ & $1.10-2.22$ \\
\hline Obesity class III x gender & 0.80 & $0.50-1.26$ & $1.44^{*}$ & $1.09-1.90$ & 1.51 & $0.94-2.45$ \\
\hline Obesity class II x age & 1.00 & $0.99-1.01$ & $1.00 *$ & $1.00-1.01$ & 0.99 & $0.98-1.01$ \\
\hline Obesity class III x age & 1.00 & $0.99-1.01$ & 1.00 & $0.99-1.01$ & 0.98 & $0.96-1.00$ \\
\hline Obesity class II x elementary education & 0.99 & $0.80-1.22$ & 0.92 & $0.78-1.09$ & 0.88 & $0.59-1.33$ \\
\hline Obesity class III x elementary education & 1.06 & $0.81-1.39$ & 0.85 & $0.68-1.06$ & 0.87 & $0.51-1.47$ \\
\hline Obesity class II x married & 1.14 & $0.92-1.40$ & 0.94 & $0.80-1.10$ & 1.05 & $0.75-1.48$ \\
\hline Obesity class III x married & 1.10 & $0.84-1.44$ & 1.18 & $0.95-1.46$ & 1.15 & $0.72-1.83$ \\
\hline \multicolumn{7}{|l|}{ Third order interactions } \\
\hline Obesity class II x gender $x$ age & c & c & $0.97 *$ & $0.95-0.99$ & c & c \\
\hline Obesity class III x gender $x$ age & c & c & 1.01 & $0.98-1.03$ & c & c \\
\hline
\end{tabular}


Table 4. Regression models for medical comorbidities ( $n=13305)$

\begin{tabular}{|c|c|c|c|c|}
\hline & \multicolumn{2}{|c|}{ Diabetes II } & \multicolumn{2}{|c|}{ Hypertension } \\
\hline & OR & $95 \% \mathrm{Cl}$ & OR & $95 \% \mathrm{Cl}$ \\
\hline \multicolumn{5}{|l|}{ Univariate regressions } \\
\hline Obesity class IIa & $1.17^{*}$ & $1.01-1.35$ & $1.55^{*}$ & $1.39-1.73$ \\
\hline Obesity class III & $1.72^{*}$ & $1.45-2.05$ & $2.40^{*}$ & $2.10-2.73$ \\
\hline Gender $^{b}$ & $0.73 *$ & $0.61-0.87$ & 0.91 & $0.80-1.03$ \\
\hline Age & $1.08 *$ & $1.07-1.08$ & $1.10^{*}$ & $1.09-1.10$ \\
\hline Elementary education & $0.41^{*}$ & $0.36-0.46$ & $0.51 *$ & $0.47-0.57$ \\
\hline Married & $1.40 *$ & $1.23-1.60$ & $1.35^{*}$ & $1.22-1.48$ \\
\hline Depressive symptoms & $1.40^{*}$ & $1.20-1.64$ & $1.34^{*}$ & $1.19-1.51$ \\
\hline Anxiety symptoms & $0.79 *$ & $0.69-0.88$ & $0.85^{*}$ & $0.77-0.94$ \\
\hline Alcohol use & $0.47^{*}$ & $0.33-0.67$ & 0.55 & $0.43-0.70$ \\
\hline \multicolumn{5}{|l|}{ Second order interactions } \\
\hline Obesity class II x gender & 0.91 & $0.60-1.39$ & 1.14 & $0.86-1.52$ \\
\hline Obesity class III x gender & 0.68 & $0.40-1.14$ & 0.81 & $0.57-1.15$ \\
\hline Obesity class II x age & 0.99 & $0.97-1.00$ & 0.99 & $0.97-1.00$ \\
\hline Obesity class III x age & 0.98 & $0.96-1.00$ & 0.99 & $0.98-1.01$ \\
\hline Obesity class II x elementary education & 1.25 & $0.93-1.68$ & 0.93 & $0.75-1.16$ \\
\hline Obesity class III x elementary education & 1.14 & $0.80-1.63$ & 0.97 & $0.75-1.26$ \\
\hline Obesity class II x married & 0.93 & $0.69-1.26$ & 0.95 & $0.77-1.19$ \\
\hline Obesity class III x married & $1.53^{*}$ & $1.06-2.19$ & 1.15 & $0.88-1.49$ \\
\hline Obesity class II $\mathrm{x}$ depression & 1.01 & $0.70-1.45$ & 0.98 & $0.75-1.29$ \\
\hline Obesity class III x depression & 1.25 & $0.83-1.88$ & 1.01 & $0.74-1.39$ \\
\hline Obesity class $\| \mathrm{x}$ anxiety & 0.96 & $0.71-1.30$ & 1.09 & $0.88-1.36$ \\
\hline Obesity class III x anxiety & 1.36 & $0.96-1.94$ & 1.01 & $0.78-1.32$ \\
\hline Obesity class II x alcohol use & 1.59 & $0.74-3.43$ & 1.47 & $0.86-2.52$ \\
\hline Obesity class III $x$ alcohol use & 0.56 & $0.16-1.99$ & 1.07 & $0.54-2.10$ \\
\hline
\end{tabular}

In the logistic regression analysis for medical comorbidities, obesity class, demographic variables, and psychiatric comorbidities were significant. The only significant second order interaction was obesity class III by being married for diabetes (table 4).

\section{DISCUSSION AND CONCLUSION}

The present study aimed to assess the prevalence of psychiatric symptoms and the interactions between obesity and demographic variables, and to determine its association with medical comorbidities in a sample of patients with obesity seeking treatment for weight loss.

It was found in univariate analysis that the probability of anxiety and depression symptoms increase as the obesity class increased; however, that relation was found to have an opposite direction with alcohol use. When analyzing second order interactions between demographics and obesity class it was found that men with class III obesity had more probability for anxiety symptoms when compared to men with obesity class I and II; for women with obesity class I, there is a direct relationship between the age and the probability of anxiety symptoms, when compared to women with obe- sity class II and III. These results are consistent with previous studies, $10,13,21,27$ suggesting that the increase in BMI is associated with the probability of depression and anxiety symptoms, ${ }^{13}$ suggesting that such relationships are moderated by the interaction of gender and age, implying that the effect of obesity in mental health varies across gender and age groups.

Men with obesity class I displayed higher odds for alcohol use when compared with obesity class II and III. This finding might support the hypothesis that compulsive eating and substance use compete for the same circuits in the reward system, hence, as one behaviour increases the other is less likely to occur. ${ }^{34,35}$ The main common factor between eating and substance use is dopamine release in the mesolimbic pathway, as the eating habits and the rewarding properties of food lead to neuroadaptation of the reward, motivation, and decision-making circuits, resulting in a subsequent loss of control and compulsive behaviours. However the opioid, GABAergic, or cannabinoid systems are implicated too. ${ }^{35-38}$ Previous evidence strongly suggests that substance use and food compete in the reward system; taking into account that food consumption is much more complex, it is plausible that the brain adaptation to overeating is harder compared to substance use. ${ }^{35}$ 
The characteristics of the sample are another relevant finding, as most were women with an age around 42 years old, with elementary education and married. When we consider global (men 37\% and women 38\%) and Mexican (men $26.5 \%$ and women $37.5 \%$ ) obesity rates, ${ }^{2}$ it is clear that there is an important difference in the rates by gender of individuals seeking treatment for obesity when compared to the national and global men to women ratio. This may point to the existence of gender-specific barriers limiting the attendance of men, such as attitudes and beliefs towards health care (underestimating risks, resistance to pain, perception of invulnerability), work hours and socioeconomic status, ${ }^{39,40}$ the age, education, and marital status of the sample. This implies that there are particular profiles of patients using this service, therefore it is necessary to develop tailored interventions based on these variables; for instance, as the majority of the patients were married and had an elementary education, a weight reduction program focused on partner and family social support might boost the effects of the intervention. ${ }^{41,42}$ In terms of educational level, ${ }^{43-45}$ is important that the provision of information is paired with the patient's education, otherwise it might be difficult to initiate behavioural changes. This result highlights the importance of tailoring specific weight loss programs, and to develop strategies to increase men's attendance to treatment.

Future studies should focus on the complex relations between obesity and psychiatric symptoms, particularly because weight loss treatment requires dietary and behavioural changes, and such lifestyle modifications are significantly affected by psychiatric variables; this becomes clear as we see the findings of previous studies that point out that anxiety and depression symptoms increase the likelihood of sedentary lifestyles, eating unhealthy food, and binge eating. ${ }^{15,27}$

This study had the following limitations: the cross-sectional design made it impossible to determine the temporal sequence of the events, and we were unable to identify which psychiatric symptoms preceded obesity. A second limitation is that the measurement of psychiatric symptoms used a single question instead of using a structured interview or a validated scale, thereby limiting the internal validity of the results, and implying that future studies will require the use of these measurements. A third limitation is that the method to diagnose hypertension, diabetes II and dyslipidemia is unclear for every patient, resulting in a probable underestimation of their prevalence.

Finally, this is one of the few studies in Mexico using a considerable clinical sample allowing testing of complex interactions between variables. This study also points out important patient characteristics that enable us to understand particular requirements needed for tailoring treatment. These results highlight that the complexity of the relationship between demographics, obesity, and psychiatric symptoms might be decisive for the outcomes in weight loss treatment; ${ }^{46,47}$ however, it seems necessary to conduct more studies using longitudinal designs and assessing other relevant psychiatric disorders, such as attention deficit and hyperactivity disorder. ${ }^{48}$ In conclusion, weight loss treatment programs must take into account the interaction between psychiatric symptoms, gender, and educational level, to boost treatment adherence ${ }^{25,26}$ and weight reduction, finally having an impact on the treatment costs and the patient's quality of life. ${ }^{49}$

\section{Funding}

None.

\section{Conflict of interests}

All sites enrolled in this study are part of a community prevention and treatment program for obesity and weight loss funded indirectly by the pharmaceutical laboratory PRODUCTOS MEDIX ${ }^{\circledR}$, through strategic agreements with public institutions for the implementation of the program.

The authors had no role in the implementation of this treatment program. The authors state that they have signed an agreement with pharmaceutical laboratory PRODUCTOS MEDIX ${ }^{\circledR}$ to analyze the database. The authors declare that they did not receive any payment or other kind of retribution for writing this academic work. The pharmaceutical laboratory PRODUCTOS MEDIX ${ }^{\circledR}$ had no role in data analysis, interpretation of results, writing process or the decision to submit this paper for publication. Therefore, the academic opinions presented in this paper are responsibility of the authors.

\section{Acknowledgments}

A special acknowledgment to pharmaceutical laboratory PRODUCTOS MEDIX ${ }^{\circledR}$ for sharing the clinical database needed to write this article.

\section{REFERENCES}

1. Ng M, Fleming T, Robinson M, Thomson B et al. Global, regional, and national prevalence of overweight and obesity in children and adults during 1980-2013: a systematic analysis for the Global Burden of Disease Study 2013. Lancet 2014;384(9945):766-781. doi:10.1016/S01406736(14)60460-8

2. Barquera CS, Nonato CI, Rojas R, Rivera J. Obesidad en México: epidemiología y políticas de salud para su control y prevención. Gac Méd Mex 2010;146:397-407.

3. De Schutter A, Lavie CJ, Milani RV. The impact of obesity on risk factors and prevalence and prognosis of coronary heart disease - the obesity paradox. Prog Cardiovasc Dis 2014;56(4):401-8. doi:10.1016/j. pcad.2013.08.003

4. Ezzati M, Lopez AD, Rodgers A, Vander Hoorn S et al. Murray CJL. Selected major risk factors and global and regional burden of disease. Lancet. 2002;360(9343):1347-1360. doi:10.1016/S0140-6736(02)11403-6

5. Laditka SB, Laditka JN. Active life expectancy of Americans with diabetes: Risks of heart disease, obesity, and inactivity. Diabetes Res Clin Pr 2015;107(1):37-45. doi:10.1016/j.diabres.2014.10.008

6. Poirier P, Giles TD, Bray GA, Hong $Y$ et al. Obesity and cardiovascular disease: pathophysiology, evaluation, and effect of weight loss: 
an update of the 1997 American Heart Association Scientific Statement on Obesity and Heart Disease from the Obesity Committee of the Council on Nutrition, Physical Activity Metabolism. Circulation 2006;113(6):898-918. doi: 10.1161/CIRCULATIONAHA.106.171016

7. Freedman DM, Ron E, Ballard-Barbash R, Doody MM et al. Body mass index and all-cause mortality in a nationwide US cohort. Int J Obesity 2006;30(5):822-829. doi:10.1038/sj.ijo.0803193

8. Olshansky SJ, Passaro DJ, Hershow RC, Layden J et al. A potential decline in life expectancy in the United States in the 21st Century. New Engl J Med 2005;352(11):1138-1145. doi: 10.1056/NEJMsr043743

9. Zhang C, Rexrode KM, van Dam RM, Li TY et al. Abdominal obesity and the risk of all-cause, cardiovascular, and cancer mortality: sixteen years of follow-up in US women. Circulation 2008;117(13):1658-1667. doi: 10.1161/CIRCULATIONAHA.107.739714

10. Jung $H$, Chang $C$. Is obesity related to deteriorating mental health of the U.S. working-age population? J Behav Med 2015;38(1):81-90. doi: 10.1007/s10865-014-9580-7

11. Kessler RC, McGonagle KA, Zhao S, Nelson CB et al. Lifetime and 12-month prevalence of DSM-III-R psychiatric disorders in the United States. Results from the National Comorbidity Survey. Arch Gen Psychiatry 1994;51(1):8-19. doi:10.1001/archpsyc.1994.03950010008002

12. Stunkard AJ, Faith MS, Allison KC. Depression and obesity. Biol Psychiatry 2003;54(3):330-337. doi:10.1016/S0006-3223(03)00608-5

13. Brumpton $B$, Langhammer A, Romundstad $P$, Chen $Y$ et al. The associations of anxiety and depression symptoms with weight change and incident obesity: The HUNT Study. Int J Obesity 2013(9):1268-1274. doi:10.1038/ijo.2012.204

14. Gariepy G, Nitka D, Schmitz N. The association between obesity and anxiety disorders in the population: a systematic review and meta-analysis. Int J Obesity 2010;34(3):407-419. doi:10.1038/ijo.2009.252

15. Luppino FS, de Wit LM, Bouvy PF, Stijnen T et al. Overweight, obesity, and depression: a systematic review and meta-analysis of longitudinal studies. Arch Gen Psychiatry 2010;67(3):220-229. doi:10.1001/ archgenpsychiatry.2010.2.

16. Markowitz S, Friedman MA, Arent SM. Understanding the Relation Between Obesity and Depression: Causal Mechanisms and Implications for Treatment. Clin Psychol-Sci Pr 2008;15(1):1-20.doi: 10.1111/j.1468-2850.2008.00106.x

17. Nigatu YT, Reijneveld SA, de Jonge P, van Rossum E et al. The combined effects of obesity, abdominal obesity and major depression/anxiety on health-related quality of life: the LifeLines Cohort Study. Plos One 2016;11(2):e0148871-e. doi: 10.1371/journal.pone.0148871

18. Scott KM, Bruffaerts R, Simon GE, Alonso $J$ et al. Obesity and mental disorders in the general population: results from the world mental health surveys. Int J Obesity 2008;32(1):192-200. doi:10.1038/ sj.ijo.0803701

19. de Wit LM, Luppino F,van Straten A, Penninx B et al. Depression and obesity: A meta-analysis of community based studies. Psychiatry Res 2010;178(3);230-205. doi:10.1016/j.psychres.2009.04.015

20. Klinitzke G, Steinig J, Blüher M, Kersting A et al. Obesity and suicide risk in adults - A systematic review. J Affect Disorders 2013;145(3):277284. doi:10.1016/j.jad.2012.07.010

21. Barry D, Petry NM. Associations between body mass index and substance use disorders differ by gender: results from the National Epidemiologic Survey on Alcohol and Related Conditions. Addict Behav 2009;34(1):51-60. doi:10.1016/j.addbeh.2008.08.008

22. Freedman DM, Sigurdson AJ, Rajaraman P, Doody MM et al. The Mortality Risk of Smoking and Obesity Combined. Am J Prev Med 2006;31(5):355-62. doi:10.1016/j.amepre.2006.07.022

23. Ma J, Jemal A, Flanders WD, Ward EM. Joint association of adiposity and smoking with mortality among U.S. adults. Prev Med 2013;56(3/4):178-184. doi:10.1016/j.ypmed.2012.12.012

24. Li L, Wu L-T. Substance use after bariatric surgery: A review. J Psychiatr Res 2016;76:16-29. doi:10.1016/j.jpsychires.2016.01.009

25. Huang H, Russo J, Bauer AM, Chan Y-F et al. Depression care and treatment in a chronically ill Medicare population. Gen Hosp Psychiatry 2013;35(4):382-386. doi:10.1016/j.genhosppsych.2013.02.006

26. Katon W, Ciechanowski P. Impact of major depression on chronic medical illness. J Psychosom Res 2002;53(4):859-863. doi: 10.1016/ S0022-3999(02)00313-6

27. Faith MS, Matz PE, Jorge MA. Obesity-depression associations in the population. J Psychosom Res 2002;53(4):935-942. doi:10.1016/S00223999(02)00308-2

28. Friedman MA, Brownell KD. Psychological correlates of obesity: Moving to the next research generation. Psychol Bull 1995;117(1):3-20. doi: 10.1037/0033-2909.117.1.3

29. Gutiérrez J, Rivera-Dommarco J, Shamah-Levy T, Villalpando-Hernández S et al. Encuesta Nacional de Salud y Nutrición 2012. Resultados Nacionales [National Health and Nutrition Survey 2010]. Cuernavaca, México. 2012.

30. Padilla-Téllez E, Ruiz García J, Rodríguez-Orozco AR. Asociación depresión-obesidad. Salud Publica Mexico 2009;51(4):275-276. doi: 10.1590/S0036-36342009000400001

31. Lazarevich I, Irigoyen-Camacho ME, Velázquez-Alva MC. Obesity, eating behaviour and mental health among university students in Mexico city. Nutr Hosp 2013;28(6):1892-1899. doi: 10.3305/nh.2013.28.6.6873

32. Worster A, Haines T. Advanced statistics: understanding medical record review (MRR) studies. Acad Emerg Med 2004;11(2):187-192. doi: 10.1111/j.1553-2712.2004.tb01433.x

33. World Health Organization. Obesity and overweight [Fact sheet No311]. 2015 [cited 2015 10/03]. Available from: http://www.who.int/ mediacentre/factsheets/fs311/en/.

34. Simansky KJ. NIH symposium series: Ingestive mechanisms in obesity, substance abuse and mental disorders. Physiol Behav 2005;86(12):1-4. doi:10.1016/j.physbeh.2005.06.016

35. Volkow ND, Wise RA. How can drug addiction help us understand obesity? Nat Neurosci 2005(5):555-560. doi:10.1038/nn1452

36. Wang G-J, Volkow ND, Logan J, Pappas NR et al. Brain dopamine and obesity. Lancet 2001;357(9253):354-357. doi:10.1016/S0140-6736(00)03643-6

37. Wang G-J, Volkow ND, Telang F, Jayne $M$ et al. Exposure to appetitive food stimuli markedly activates the human brain. Neuroimage 2004;21(4):1790-1797. doi:10.1016/j.neuroimage.2003.11.026

38. Volkow ND, Fowler JS, Wang G-J. The addicted human brain: insights from imaging studies. J Clin Invest 2003;111(10):1444-1451. doi:10.1172/ JCI18533.

39. Gough B, Conner MT. Barriers to healthy eating amongst men: a qualitative analysis. Soc Sci Med 2006;62(2):387-395. doi:10.1016/j. socscimed.2005.05.032

40. Galdas PM, Cheater F, Marshall P. Men and health help-seeking behaviour: literature review. J Adv Nurs 2005;49(6):616-623. doi: 10.1111/j.1365-2648.2004.03331.x

41. Kiernan M, Moore SD, Schoffman DE, Lee K et al. Social support for healthy behaviors: scale psychometrics and prediction of weight loss among women in a behavioral program. Obesity 2012;20(4):756-764. doi: 10.1038/oby.2011.293

42. The Look AHEAD Research Group. The Look AHEAD Study: A Description of the lifestyle intervention and the evidence supporting it. Obesity 2006;14(5):737-752.doi: 10.1038/oby.2006.84

43. Moroshko I, Brennan L, O'Brien P. Predictors of dropout in weight loss interventions: a systematic review of the literature. Obes Rev 2011;12(11):912-934. doi: 10.1111/j.1467-789X.2011.00915.x

44. Bradshaw AJ, Horwath CC, Katzer L, Gray A. Non-dieting group interventions for overweight and obese women: what predicts non-completion and does completion improve outcomes? Public Health Nutr 2010;13(10):1622-1628.doi: 10.1017/S1368980009992977

45. Elfhag K, Rössner S. Initial weight loss is the best predictor for success in obesity treatment and sociodemographic liabilities increase risk for dropout. Patient Educ Couns 2010;79(3):361-366. doi:10.1016/j.pec.2010.02.006

46. Ogden J. The correlates of long-term weight loss: a group comparison study of obesity. Int J Obesity 2000;24(8):1018-1025. 
47. Jerome GJ, Myers VH, Young DR, Matthews-Ewald MR et al. Psychosocial predictors of weight loss by race and sex. Clin Obesity 2015(6):342-348. doi: 10.1111/cob.12120

48. Cortese S, Moreira-Maia CR, St. Fleur D, Morcillo-Peñalver $C$ et al. Association between ADHD and obesity: a systematic review and meta-analysis. Am J Psychiat 2016;173(1):34-43. doi: 10.1176/appi. ajp.2015.15020266
49. Mazzeschi C, Pazzagli C, Buratta L, Reboldi GP et al. Mutual interactions between depression/quality of life and adherence to a multidisciplinary lifestyle intervention in obesity. J Clinical Endocrinology Metabolism 2012;97(12):E2261-E2265. doi: 10.1210/jc.2012-2364 